\title{
Development of New Vaccine - New Method to Prepare Artificial Membrane Vaccine using Inter-Membrane Protein Transfer
}

\author{
Masaharu Ueno* and Kyoko Hayashi \\ Graduate School of Pharmaceutical Sciences, University of Toyama, 2630 Sugitani, Toyama 930-0194, Japan
}

\begin{abstract}
Influenza is one of the common infectious diseases caused by influenza virus. Vaccines are the most effective means to fight infectious diseases. While these vaccines are quite effective in young adults, however, they are less for the above high risk group. A currently used influenza vaccine contains aluminum hydroxide as an adjuvant, which sometimes induces the production of IgE antibodies causing an allergic reaction. In order to overcome the drawbacks, artificial membrane vaccines or liposome vaccines have been developed. Liposomes are known to be effective immunoadjuvants. On the other hand, various membrane proteins, including matrix membrane proteins, have been reported to be spontaneously transferrable from living cell membranes to artificial membranes (liposomes). In this article, we introduced a new method to prepare the artificial membrane vaccine, "influenza virosomes", using inter-membrane protein transfer, and discussed the immunreactivity of the virosomes. We concluded that the application of inter-membrane protein transfer technique is a useful method for the preparation of the artificial membrane vaccine, virosomes. The virosomes showed high immunoreactivity especially with MDP (muramyldipeptide) derivatives as an adjuvant or booster treatment.
\end{abstract}

Keywords: Influenza, vaccine, liposomes, virosomes, inter-membrone protein transfer.

\section{INTRODUCTION}

Influenza is one of the common infectious diseases, which is caused by influenza virus and spread mainly in the late fall and winter. It differs from the common cold in high fever, headaches and extreme exhaustion. It is possible to become mortal disease for high risk group including the elderly, infants and the patients suffering from chronic diseases $[1,2]$. It is said that in the United States of America more than 200,000 people are hospitalized and about 36,000 people die from influenza every year. Vaccines are the most effective means to fight infectious diseases. Commonly used influenza vaccines are inactivated whole virions, split virions or subunit antigen vaccine. While these vaccines are quite effective in young adults, however, they are less for the above high risk group [3]. It has been known that the more purified the antigenic proteins are, the less effective the antigenic activity becomes [4-7]. To enhance antigenic activity Alum (aluminum hydroxide) has been used as an adjuvant, but Alum is known to induce production of IgE antibodies which often causes allergic reaction [8]. On the other hand, it has been found that liposomes can be effective immunoadjuvants [9-14]. In order to overcome the drawbacks mentioned above, artificial membrane vaccines or liposome vaccines have been developed [15-17].

\section{1) ARTIFICIAL MEMBRANE VACCINE OR LIPOSOME VACCINE}

Artificial membrane vaccines have shown high antibody titers against hemmaglutinin (HA) compared to the currently

\footnotetext{
*Address correspondence to this author at the Graduate School of Pharmaceutical Sciences, University of Toyama, 2630 Sugitani, Toyama 930-0194, Japan; Fax: +81-76-434-5050;

E-mail: mueno@pha.u-toyama.ac.jp
}

used influenza vaccine and have low side effects. Clinical trials have also shown high immune response even in elderly people $[18,20]$. Thus, artificial membrane vaccines are expected to be one of the most promising new types of vaccines. It has been reported that different modes of antigen association with liposomes, encapsulated and surface-linked, show different immunoreactivity [21,22]. Surface-linked liposomal peptide has been shown to serves as an effective vaccine without showing detrimental effects in the presence of immune potentiators $[23,24]$. Furthermore, influenza virosomes enhanced CTL (cytotoxic T lymphocyte) induction [25-27].

To reconstitute a transmembrane protein of cells on an artificial membrane, various detergents or organic solvents have generally been used. However, treatment with detergents or organic solvents possibly causes denaturation and inactivation of the target protein. In addition, the antigens were equally incorporated into the outer and inner leaflets of the liposomes by the currently used reconstitution methods. This has resulted in the reduction of the advantage of using liposomal vaccines. Recently, it has been reported that various membrane proteins are transferred spontaneously from cell to liposomal membranes without the solubilization and reconstitution steps using detergents or organic solvents [29-42].

\section{2) SPONTANEOUS TRANSFER OF MEMBRANE PROTEINS FROM CELLS TO LIPOSOMES.}

In early years, transfer of cytochrome $b_{5}$, which binds to the membrane surface due to its hydrophobic tail, was studied by many investigators [29-34]. This protein was considered to pass from cells to liposomes in the following manners: the protein is released into an aqueous phase from the cell membrane as monomer, and is transferred to 
liposomes, favorably to small unilamellar vesicles rather than to large vesicles. Huestis and his coworkers' studies focused on the transfer of more integrated proteins of cell membranes [35-37]. They reported that band 3 protein could transfer spontaneously from erythrocytes to liposomes, and the transferred band 3 protein in liposomes held a similar orientation in lipid bilayer as in the erythrocytes and original activity. In order to elucidate the above phenomena, they proposed a model where in transient fusion occurred between the cell membrane and liposomal membrane [37]. Furthermore they reported that inter-membrane protein transfer was enhanced by perturbing the lipid environment around the protein or membrane defect of donor cells caused by the penetration of recipient lipids or surfactant such as cholate, and that acetylcholine esterase transfers more to liposomes when the recipient membrane is more fluid than the donor [35-41]. Sunamoto and his coworkers reported that the addition of an artificial lipid 1,2-dimyristoylamido-1,2deoxyphosphatidylcholine (DDPC) into phosphatidylcholine (PC) liposomes enhanced protein transfer from biological membranes such as erythrocytes and platelets [39,40,42]. They considered that the reason for the effect of DDPC on protein transfer was the enhancement of the holding ability of the transferred protein into the recipient membrane by intermolecular hydrogen bonding of those lipids $[43,44]$. Spontaneous protein transfer was not restricted to that from cells to liposomes. We found that HA protein on the CV-1 cells infected with influenza virus could transfer to erythrocyte membrane ghosts [45]. We succeeded in a protein (superoxide dismutase) delivery from the proteinencapsulated erythrocyte ghost to living cells (CV-1 and HeLa cells) by taking advantage of the fusing ability of the HA protein incorporated into the erythrocyte ghost membranes [46-48]. Recently, Niu et al., reported that a vriety of transmembrane proteins and other cellular components are transferable between multiple cell types, which were induced by transient local membrane fusion [49]. Thus, many investigations have been done about spontaneous membraneprotein transfer from cell membranes to artificial membranes such as liposomes, or cell to cell. On the other hand, there are some reports which refute spontaneous protein transfer, such as how no spontaneous transfer of the GPI-linked protein occurs at all [50]. Although clear explanation for the mechanism of spontaneous protein transfer from biological membranes to liposomes and its regulating factors have not been established yet, this idea has much possibility as a new method of reconstituting membrane proteins on artificial membrane. We started to study on the development of new method to prepare liposome vaccines, virosomes, against the influenza virus adopting the application of the intermembrane protein transfer.

\section{3) CONSTRUCTION OF INFLUENZA VIROSOMES USING SPONTANEOUS PROTEIN TRANSFER AND THEIR BIOLOGICAL ACTIVITY AS AN ARTIFICIAL MEMBRANE VACCINE}

Experimental procedures [51] were as follows: CV-1 cells from monkey kidney were infected with influenza virus (A/NWS/33, H1N1 subtype). CV-1 celles and the virus were obtained from Denka Seiken Co. Ltd. (Niigata, Japan). After incubation at $37^{\circ} \mathrm{C}$ for $20-24 \mathrm{~h}$, liposomes were added and further incubated for proper time. The liposomes were recovered and the transferred antigenic proteins $\mathrm{HA}$ and NA (neuraminidase) were monitored. Immunoactivity of HA, NA-incorporated liposomes (virosomes or artificial membrane vaccine) was evaluated.

First, how much protein could be recovered on the liposomal membrane in all released protein was studied. In higher temperature more proteins $[51,52]$ were released. The recovered protein seemed to be almost proportional to the released protein in each temperature and was about $20 \%$ of all released protein [51]. The transfer efficiency was influenced by several factors, such as lipid composition of acceptor liposomes, liposome size, incubation temperature and so on. For recipient liposome size, the recovered protein was highest on SUV (small unilamellar vesicle) [53] in accord with the previous report regarding transfer of cytochrome $b_{5}$ [34-34]. For lipid composition, the incorporation of DCP (dicetylphosphate), DPPS (dipalmitoylhosphatidylserine) and DMDPA (dimethyldipalmitoylammonium) into DMPC (dimyristoylphosphatidylcholine) liposomes enhanced protein transfer. On the other hand DPPC (dipalmitoylphosphatidylcholine) and bbPS (bovine brain phosphatidylserine) had no effect on protein transfer. DCP and DPPS were anionic lipids, and DMDPA was a cationic lipid. DPPS and bbPS have the same head group [54]. These results show that electrostatic condition does not significantly affect the protein transfer, consisting with a report of Waters et al., [41]. Instead, the phase separation of recipient vesicles might enhance inter-membrane protein transfer allow for the common property of the membranes composed of mixture of DMPC and DCP, DMPC and DPPS or DMPC and DMDPA which was in the state of phase separation at $37^{\circ} \mathrm{C}$ [55]. In addition, membrane fluidity did not crucially affect protein transfer [54]. Two influenza virus-specific proteins, HA and NA, which were present on the membrane of virus-infected $\mathrm{CV}-1$ cells, were also transferred from the cell membrane to liposomes as shown in the Western blotting[53] and SDS (sodium dodecyl sulfate)-PAGE (polyacrylamid gel electrophoresis) after immunoprecipitation [52]. As shown in Fig. (1), three proteins, HA1, HA2 and NA, were detected. In order to know the distribution and localization of transferred viral proteins on the liposomal membranes, fluorescent images of the liposomes were observed using FITC (fluorescein isothiocyanate)-labeled antibody and freeze-fracture electron micrograph. RITC (rhodamine B isothiocyanate) dextran-incorporated REV (reverse-phase evaporation vesicle) liposomes were incubated with the influenza virus infected-CV-1 cells, and the liposomes were collected by centrifugation. The liposomes were treated with a primary antibody (rabbit anti-influenza virus antibody) followed by a secondary antibody (FITC labeled anti-rabbit IgG antibody). As shown in Fig. (2) [56], the fluorescences of RITC and FITC were observed throughout entire liposomes, suggesting that transferred antigenic proteins were distributed all over the membrane surfaces of the liposomes. As shown in Fig. (3) [57], spikes of viral proteins on the liposomal membranes were observed just like influenza virus particles on freeze fracture electron micrograph, suggesting that transferred viral proteins were aligned in a similar manner as influenza virus particles. In searching for the mechanism of inter-membrane protein transfer, two pathways were assumed: one was direct transfer by contact of liposomal membranes with cell 


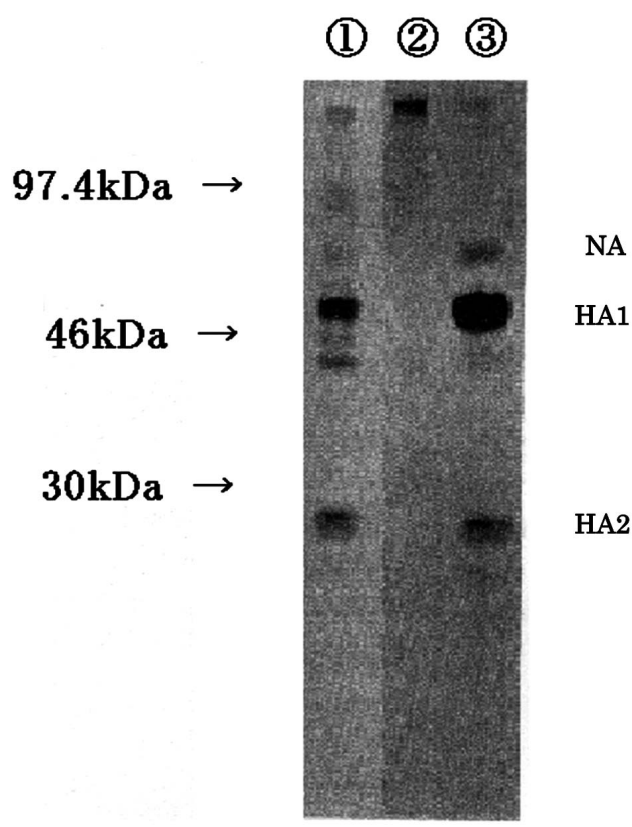

Fig. (1). Detection of influenza virus glycoproteins by SDS PAGE after immunoprecipitation. Lane 1: influenza virusinfected CV-1 cells. Lane 2: liposomes incubated with CV-1 cells. Lane 3: liposomes incubated with influenza virus-infected CV-1 cells.
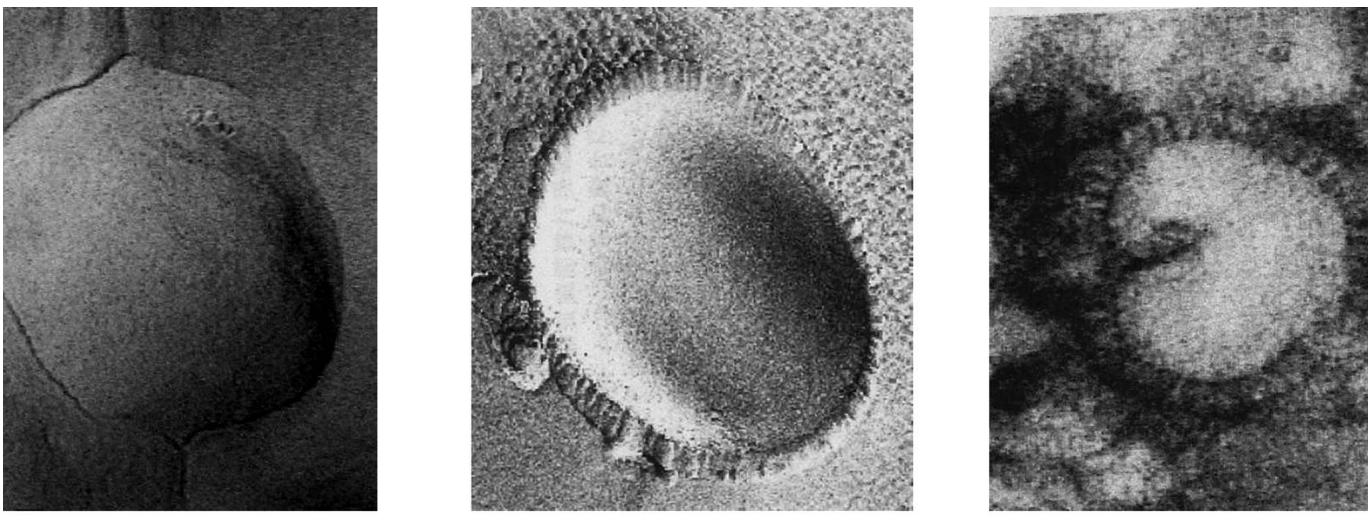

\section{A) control liposomes}

C) influenza virus
Visible light

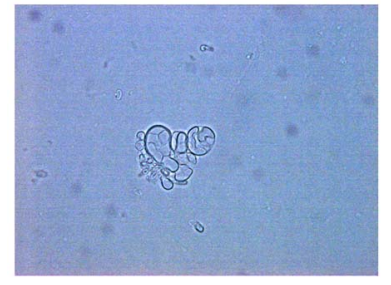

RITC

FITC
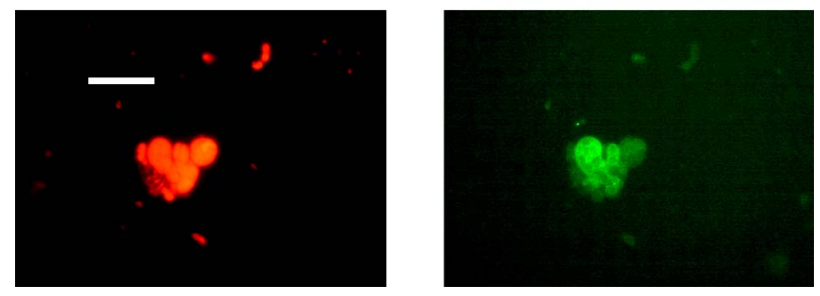

Fig. (2). Visible light and fluorescent images of REV (reversephase evaporation vesicle) liposomes incubated with influenza virus-infected CV-1 cells. Visible: vsible light image. RITC: fluorescent image of RITC-labeled dextran encapsulated in the liposomes. FITC: fluorescent image of FITC-labeled antibody $\left(2^{\text {nd }}\right.$ antibody).

\section{B) liposomes incubated with infected cells}

Fig. (3). Freeze-fracture electronmicrographs of control liposome and liposome incubated with infected cells; A) Original liposome before incubation; B) virosome after incubation with influenza virus-infected CV-1 cells; C) negative-staining electron-microrograph of influenza virus.

membranes (Huestis' model); the other was protein transfer from the medium to liposomes after proteins on the cell membrane had been released into the medium. In order to verify the latter case experimentally, the virus-infected cells were incubated in the medium (sorting buffer) in the absence of liposomes for $1 \mathrm{~h}$ at $37^{\circ} \mathrm{C}$. After removing the cells by centrifugation the liposomes were added to the medium. The membrane proteins could be recovered into the liposomes in this experiment, although the quantity of transferred proteins in the latter case was about half of that in former case. The transferred proteins in the latter case were about one third of released protein. The virus specific proteins transferred from $\mathrm{CV}-1$ cells to liposomal membrane was monitored by immuno precipitation. In both cases, a band, which was assigned to influenza virus protein (HA1), was observed on an autoradiograph image after immuno precipitation (Fig. 4) [57]. Above results showed that there should be another pathway in addition to Huestis' model.

The above prepared proteoliposomes were injected intraperitoneally to BALB/c mice as an artificial membrane vaccine, and the titers of neutralizing antibodies in sera were measured at 1,2 and 3 weeks after immunization [58]. The booster effect was also examined by injecting the artificial membrane vaccine 2 weeks after the first immunization. The results were shown in Fig. (5) [58]. After 1 week of immunization, antibody titer in mice treated with the inactivated virus (positive control group) was higher than that of the positive liposomes (viral protein-incorporated liposomes). However, 2 weeks after immunization, antibody 
titers in the positive liposome group were comparable to that of positive control group, especially, after booster treatment. In another experiment, a muramyl dipeptide derivative, B30-
MDP, was added as an adjuvant in the liposome preparation, potent adjuvant activity was observed by B30-MDP in a dose-dependent manner (Fig. 6) [58].

\section{(1) (2) (3) (4)}

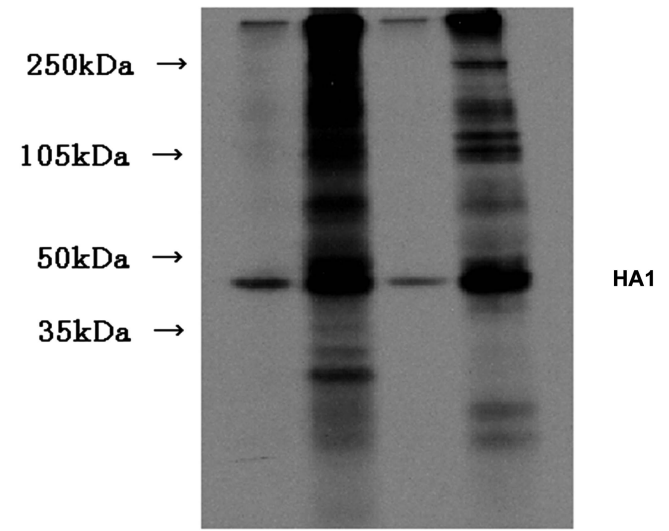

Fig. (4). Detection of influenza virus glycoproteins by SDS PAGE after immunoprecipitation in the different conditions. Lane 1: liposomes after incubation with influenza virus-infected cells; lane 2: infected cells; lane 3: liposomes after incubation with medium, which had been incubated with infected cells; lane 4: medium.

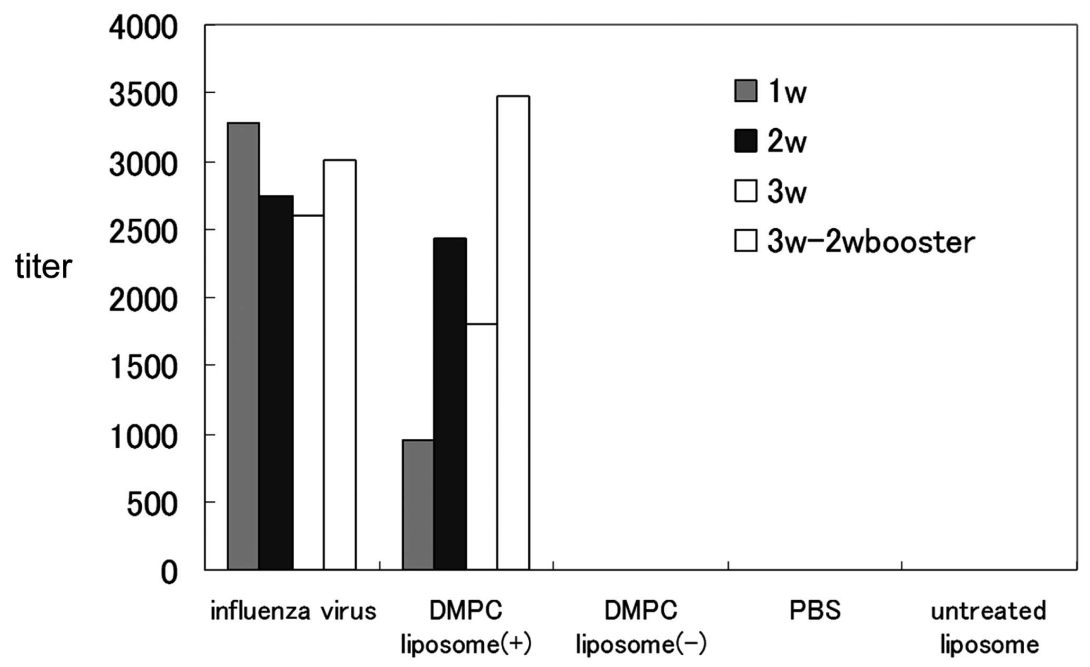

Fig. (5). Neutralizing antibody titers in sera of mice intraperitoneally administered with inactivated viruses or virosomes. DMPC Liposome $(+)$ : liposomes incubated with infected cells; DMPC liposome(-) : liposomes incubated with non-infected cells untreated liposome: liposomes not incubated with cells.

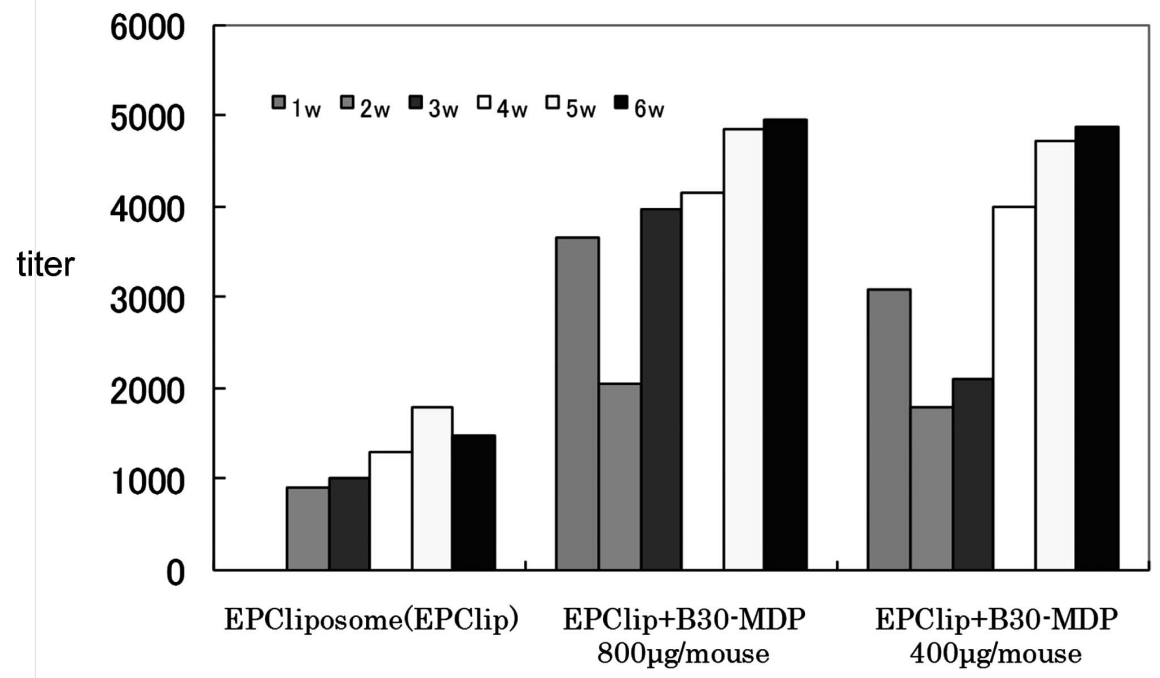

Fig. (6). Effect of B30-MDP on the production of virus-specific antibody. EPC liposomes: EPC (egg yolk phosphatidylcholine) liposomes without B30-MDP incubated with virus-infected CV-1 cells. EPC+B-30MDP: EPC liposomes containing B30-MDP. 
Next, we compared the effects of administration routes of vaccines, that is, intranasal and subcutaneous administrations, on the production of virus-specific antibody. As the vaccines, we used inactivated influenza virus, liposomes incubated with influenza virus-infected CV-1 cells (virosomes), and the mixture of virosomes and B30-MDP at the same quantity of virus-specific glycoproteins (HA and NA). These vaccines were applied to $\mathrm{BALB} / \mathrm{c}$ mice, and the neutralizing antibody against influenza virus was titrated in the sera collected 1 and 4 weeks after treatment with vaccines. As shown in Fig. (7) [56], the production of the antibody was observed in the mice treated with intranasal virosomes and the mixture of virosomes and B30-MDP as early as 1 week after vaccination, while the other groups showed very small levels of antibody. At 4 weeks of intranasal vaccination, the levels of antibody in the mice treated with the virosomes and the mixture were almost the same as that in the mice treated with inactivated virus. On the other hand, markedly high titers of antibody were obtained in the mice treated subcutaneously with the virosomes and the mixture as compared with that in inactivated virus-treated mice. From these results, it was found that virosomes could quickly stimulate the immune function of mice for the protection from virus infection.

\section{A.1 week}

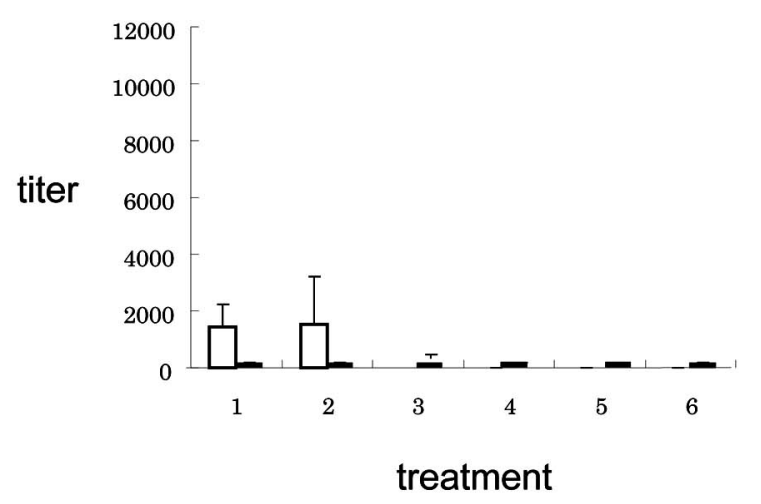

B. 4 weeks

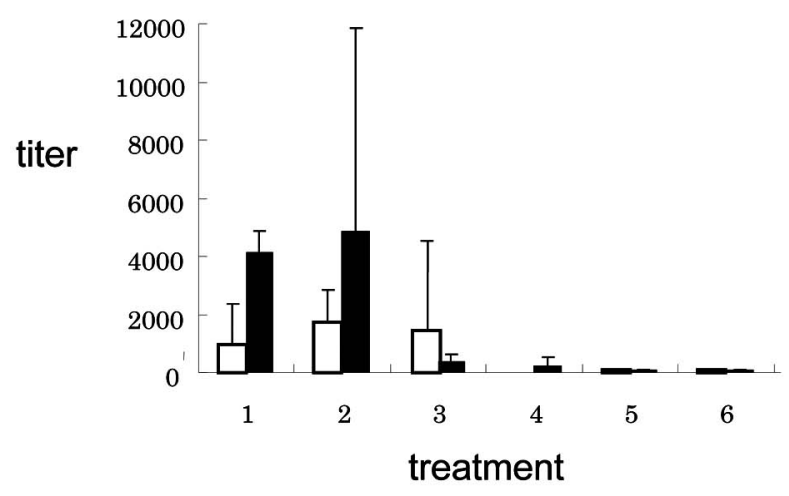

Fig. (7). Neutralizing antibody titers in sera 1 or 4 weeks after intranasal (open squares) and subcutaneous (closed squares) administration. 1. liposomes incubated with influenza virus-infected CV-1 cells (virosomes). 2. virosomes + B-30 MDP as an adjuvant. 3. inactivated virus. 4. liposomes incubated with uninfected $\mathrm{CV}-1$ cell. 5. Liposomes. 6. PBS.

\section{CONCLUSION}

Using inter-membrane protein transfer is a useful method to prepare the artificial membrane vaccine, virosomes. The virosomes showed high immunoactivity especially with MDP derivatives or booster treatment.

\section{REFERENCES}

[1] Kim HW, Brandt CD, Arrobio JO, Murphy B, Chanock RM, Parrott RH. Influenza A and B virus infection in infants and young children during the years 1957-1976. Am J Epdemiol 1979; 109: 464-79.

[2] Barker WH, Mullooly JP. Impact of epidemic type A influenza in a defined adult population. Am J Epidemiol 1980; 112: 798-811.

[3] Keren G, Segev S, Morag A, Zakay-Rones Z, Barzilai A, Rubinstein E. Failure of influenza vaccination in the aged. J Med Virol 1988; 25: 85-9.

[4] Shapira M, Jibson M, Muller G, Arnon R. Immunity and protection against influenza virus by synthetic peptide corresponding to antigenic sites of hemagglutinin. Proc Natl Acad Sci USA 1984; 81:2461-5.

[5] Potter CW, Jennings R, Phair JP, Clark A, Stuart-Harris CH. Doseresponse relationship after immunization of volunteers with a new, surface-antigen-adsorbed influenza virus vaccine. J Infec Dis 1977; 135: 423-31.

[6] Brady MI, Furminger IG. A surface antigen influenza vaccine. 1. purification of haemaglutinin and neuraminidase proteins. J Hyg 1976; 77: 161-72.

[7] Webster RG, Glezen WP, Hannoun C, Laver WG. Potentiation of the immune response to influenza virus subunit vaccines. J Immunol 1977; 119: 2073-7.

[8] Aggerbeck H, Wantzin J, Heron I. Booster vaccination against diphtheria and tetanus in man. Comparison of three different vaccine formulations---III. Vaccine 1996; 14: 1265-72.

[9] Allison AC, Gregoriadis G. Liposomes as immunological adjuvants. Nature 1974; 252: 252.

[10] van Rooijen N, van Nieuwmergen R, Kors N. The secondary immune response against liposome associated antigens. Immunol Commun 1981; 10: 59-70.

[11] Vlasov GS, Salov VF, Torchilin VP, Berdichevskii J. Liposomes and their potential use in applied immunology. Epidemiol Microbiol Immunobiol 1982; 8: 12-9.

[12] Klein JP, Wachsmann D, Scholler M. Liposomes as immunological adjuvants for Streptococus mutants antigens. in: Gregoriadis G, ed: Liposomes as Drug Carriers, Wiley 1988; pp. 261-6.

[13] Gregoriadis G, Garcon N, Senior J, Davis D. The immunoadjuvant action of liposomes: nature of immune responces and influence of liposomal characteristics. In: Gregoriadis G, Ed: Liposomes as Drug Carriers. Wiley 1988; pp279-307.

[14] Gregoriadis G. Immunological adjuvants: a role for liposomes. Immunol Today 1990; 11: 89-97.

[15] Almedida JD, Edwards Dc, Brand CM, Heath TD. Formation of virosomes from influenza subunits and liposomes. Lancet 1975; 8: 899-901.

[16] Gregoriadis G. The liposome drug-carrier concept: its development and future. in: Gregoriadis G and Allison AC, ed: Liposoems in Biological Systems Wiley 1980; pp.25-86.

[17] Torchilin VP, Butkhanov SA, Mazhul LA, Ageeva ON. Liposomal vaccine against influenza virus. in: Gregoriadis G, Ed: Liposomes as Drug Carriers Wiley 1988; pp.229-33.

[18] Gluck R, Mischler R, Finkel B, Que JC, Scarpa B, Cryz Jr SJ. Immunogenecity of new virosome influenza vaccine in elderly people. Lancet 1994; 344: 160-3.

[19] Gluck U, Gebbe J, Gluck R. Phase 1 evaluation of intranasal virosomal influenza vaccine with and without Escherichia coli heat-labile toxin in adult volunteers. J Virol 1999; 73: 7780-6.

[20] van Slooten ML, Hayon I, Babai I, Zakay-Rones Z, Wagner E, Kedar E. Immunoadjuvant activity of interferon-gamma-lposomes co-administered with influenza vaccine. Biochim Biophys Acta 2001; 1531: 99-110.

[21] Uchida T, Taneichi M. Clinical application of surface-linked liposomal antigens. Med Chem 2008; 8: 184-92.

[22] Shahum E, Therien HM. Immunopotentiation of the humoral response by liposomes: encapsulation versus covalent linkage. Immunology 1988; 65: 315-7. 
[23] Fortin A, Shahum E, Krzystyniak K, Therien HM. Differential activation of cell-mediated immune founctions by encapsulated and surface-lenked liposomal antigens. Cell Immunol 1996; 169: 208-17.

[24] Taneichi M, Naito S, Kato H, et al. T cell-independent regulation of IgE antibody production induced by surface-linked liposomal antigen. J Immunol 2002; 169: 4246-52.

[25] Nagata $T$, Toyota $T$, Ishigaki $H$, et al. Peptide coupled to the surface of a kind of liposome protect infection of influenza virus. Vaccine 2007; 25: 4914-21.

[26] Schmacher $\mathrm{R}$, Adamina $\mathrm{M}$, Zurbriggen $\mathrm{R}$, et al. Influenza virosomes enhance class I restricted CTL induction through CD4+ T cell activation. Vaccine 2004; 22: 714-23.

[27] Taneichi M, Ishida H, Kajino K, et al. Antigen chemically coupled to the surface of liposomes are cross-presented to CD8+ T cells and induce potent antitumore immunity. Immunology 2006; 177: 232430 .

[28] Matsui M, Kohyama S, Suda T, et al. Biochem. Biophys. A CTLbased liposomal vaccine capable of inducing protection against heterosubtypic influenza virus in HLA-A*0201 transgenic mice. Res Com 2010; 391: 1494-9.

[29] Roseman MA, Holloway PW, Calabro MA, Thompson TE. Exchange of cytochrome b5 between phospholipid vesicles. J Biol Chem 1977; 252: 4842-9.

[30] Leto TL, Holloway PW. Mechanism of chytocrome b5 binding to pohosphatidylcholine vesicles. J Biol Chem 1979; 254: 5015-9.

[31] Enoch HG, Fleming PJ, Strittmatter P. The binding of cytochrome b5 to phospholipid vesicles and biological membranes. Effect of orientation on intermembrane transfer and digestion by carboxypeptidase Y. J Biol Chem 1979; 254: 6483-8.

[32] Leto TL, Roseman MA, Holloways PW, Holoway PW. Mechanism of exchange of cytochrome b5 between phosphatidylcholine vesicles. Biochemistry 1980;19: 1911-6.

[33] Greenhut SF, Roseman MA. Distribution of cytochrome b5 between sonicated phospholipid vesicles of different size. J Biol Chem 1985; 260: 5883-6.

[34] Greenhut SF, Bourgeois VR, Roseman MA. Distribution of cytochrome b5 between small and large unilamellar phospholiopid vesicles. J Biol Chem 1986; 261: 3670-5.

[35] Cook SL, Bouma SR, Huestis WH. Cell to vesicle transfer of intrinsic membrane proteins: effect of membrane fluidity. Biochemistry 1980; 19: 4601-7.

[36] Newton AC, Cook SL, Huestis WH. Transfer of band 3, the erythrocyte anion transporter, between phospholipid vesicles and cells. Biochemistry 1983; 22: 6110-7.

[37] Huestis WH, Newton AC. Intermembrane protein transfer. Band 3, the erythrocyte anion transporter, transfers in native orientation from human red blood cells into the bilayer of phospholipid vesicles. J Biol Chem 1986; 261: 16274-8.

[38] Nakamura M, Tsuji K, Katsuragi Y, Kurihara K, Sunamoto J. Taste receptor proteins directly extracted by liposome from intact epithelium of bullfrog tongue. Biochem Biophys Res Commun 1994; 201: 415-22.

[39] Okumura Y, Ishitobi M, Sobel M, Akiyoshi K, Sunamoto J. Transfer of membrane proteins from human platelets to liposomal fraction by interaction with liposomes containing an artificial boundary lipid. Biochim Biophys Acta 1994; 1194: 335-40.

[40] Suzuki K, Okumura Y, Sato T, Oki A, Oki M, Sunamoto J. Direct extraction of A and B blood group antigens from human red cells by liposomes. Transfusion 1996; 36. 966-8.
[41] Waters SI, Sen R, Brunauer LS, Huestis WH. Hysical determinants of intermembrane protein transfer. Biochemistry 1996; 35: 4002-8.

[42] Sunamoto J, Goto M, Akiyoshi K. Effective transfer of membrane proteins from human erythrocytes to artificial boundary lipidcontaining liposomes. Chem Lett 1990: 1249-52.

[43] Sunamoto J, Goto M, Iwamoyo K, Kondo H, Sato T. Synthesis and characterization of 1,2-dimylistoylamido-1,2-deoxyphosphatidylcholine as an artifical boundary lipid. Biochim Biophys Acta 1990; 1024: 209-19.

[44] Sunamoto J, Nagai K, Goto M, Lindman B. Deuterium nuclear magnetic reasonance studies on the interaction of glycophorin with 1,2-dimyristoylamido-1,2-deoxyphosphatidylcholine. Biochim Biophys Acta 1990; 1024: 220-6.

[45] Kogure K, Okuda O, Itoh T, Hayashi K, Ueno M. Development of a membrane fusible drug carrier from erythrocytoes by the spontaneous transfer of viral fusion protein from influenza virusinfected cells. Biol Pharm Bull 1997; 20: 581-3.

[46] Kogure K, Itoh T, Okuda O, Hayashi K, Ueno M. The delivery of protein into living cells by use of membrane fusible erythrocyte ghosts. Int J Pharm 2000; 210: 117-20.

[47] Ueno $M$, Kogure K. Intermembrane protein transfer and its application. Biophysics 2001; 233: 28-31.

[48] Ryuda Y. "Construction of membrane fusible erythrocyte ghost" Thesis for master degree, Toyama medical and pharmaceutical University 2002

[49] Niu X, Gupta K YJT, Shamblott, MJ, Levchenko A. Physical transfer of membrane and cytoplasmic components as a general mechanism of cell-cell communication. J Cell Sci 2009; 122: 600-10.

[50] Suzuki K, Okumura Y. GPI-linked proteins do not transfer spontaneously from erythrocytes to liposomes. New aspects of recognization of the cell membrane. Biochemistry 2000; 39: 947785.

[51] Yokota K, Tamaki S, Hayashi K, Ueno M. Basic study on development of artificial membrane vaccine using inter-membrane protein transfer. Membrane 2002; 27: 94-100.

[52] Tamaki S. Basic Study on Development of Artificial Membrane Vaccine using Inter-membrane protein Transfer. Thesis for master degree, Toyama Medical and Pharmaceutical University 2001.

[53] Kogure K, Itoh M, Hayashi, K, Ueno M. Spontaneous transfer of viral protein from membrane of influenza virus-infected celles to liposomes is dependent on the diameter of receiver. Biol Pharm Bull 1995; 18: 1168-70.

[54] Kogure K, Nakamura C, Okuda O, Hayashi K, Ueno M. Effect of dicetylphosphate or stearic acid on spontaneous transfer of protein from influenza virus-infected cells to dimyristoylphosphatidylcholine liposomes. Biochim Biophys Acta 1997; 1329: 174-82.

[55] Kogure K, Okuda O, Nakamura C, Hayashi K, Ueno M. Effect of incorporation of various amphiphiles into recipient liposome membranes on intermembrane protein transfer. Chem Pharm Bull 1990; 47: 1117-20.

[56] Siraishi T. Artificial Membrane Vaccine-Comparison between administration routs. Thesis for master degree, Toyama University 2006.

[57] Yokota K. Study on Inter-membrane Protein Transfer-Passways of protein transfer. Thesis for master degree, Toyama Medical and Pharmaceutical University 2002.

[58] Itoh N. Artificial Membrane Vaccine-Adjubant Effect of MDP Derivatives. Thesis for master degree, Toyama Medical and Pharmaceutical University 2003. 